and further unrecognized internal bleeding occurred. On analysis of the deaths from haemorrhage recently it would appear that of the previous twenty cases annually about fifteen could have been saved by transfusion, but about five each year would have died despite transfusion owing to shock or to continued bleeding.

\section{Further Requirements}

What is still required is a method of keeping blood in stock similar to the storage of saline solution in bottles for intravenous use. Patients have died within half an hour of admission. An intravenous saline injection can be started within ten minutes of admission, and blood transfusion could be started in the same time if blood were kept in storage. I have had no experience of the Russian method.

\section{Conclusion}

From the statistics of the hospital about one-fourth of the deaths are due to haemorrhage. Of these deaths from haemorrhage about three-fourths can be avoided by transfusion within one hour of adinission to hospital. This has required the organization of a blood transfusion service for this hospital. Blood transfusion services are organized in London and certain other cities, but they should be organized by every obstetrical hospital when a public service is not available. These facilities should be extended to patients too ill to be brought into hospital at once and also to private practice in the area. For the smooth working of such a service the concentration of maternity work in a large centre with a highly skilled staff is preferable.

My thanks are due to the entire medical staff of the hispital for their co-operation.

REFERENCES

Baird, D. (1936). Lancet. 1, 395.

Baker and Dodds (1930). Brit. J., exp. Path., 6, 247.

S. C. Davidson and S. L. Warren (N.Y. St. J. Med., February 15,1937, p. 387 ) review radiographs of twentyfour patients with infectious arthritis taken before and after treatment. The sole measures used were fever therapy alone or in combination with a hot bath routine. Before treatment each patient was physically examined, septic foci were removed, and an electrocardiogram and a radiograph of the chest were taken. No dietetic regulations were enforced with the exception of an additional daily intake of one quart of milk. The patient was placed in a cabinet with the radiation from five 200 -watt lamps directed at the trunk and limbs, the head remaining outside. The temperature was raised to $40.5^{\circ} \mathrm{C}$. and maintained for four hours. A hot bath routine was carried out throughout the cold months of the year. Of twenty-four patients thus treated three showed no clinical or radiological improvement; six were clinically improved, but there was no radiological evidence of definite change in the bony structures round the joint to support this improvement; thirteen showed clinical and radiological improvement. The authors analysed their cases and found that cases of infectious arthritis are resistant to fever therapy $(a)$ when the disease is in the acute stage of soft tissue proliferation, and $(b)$ when the cartilage is affected and ankylosis has developed. These are usually persons under 30 years of age. In the subacute or chronic stage of infectious arthritis with thinning of the cartilage and bone atrophy in persons between 30 and 50 years of age marked improvement resulted. Two cases with degenerative hypertrophic arthritis obtained complete relief from symptoms after fever therapy, though without any radiological evidence of diminution of bony spur formation.

\section{THE PREVENTION OF CONSTIPATION}

BY

\section{E. M. DIMOCK, M.D., B.Ch.}

The progress of medicine is towards prevention. Yet constipation, one of the commonest ailments of civilization, receives only remedies. The present attitude of the medical profession towards constipation is deplorable. Students at many hospitals are brought up in an atmosphere where the indiscriminate use of purgatives is condoned. Too often the dose and type of purgative are left to the caprice of the nursing staff, and bear no relation to the experience of the patient. Recently, however, Professor Witts (1937) has shown that the treatment of acute constipation by purgation is irrational, and his article should be read by every doctor and nurse. As a general practitioner I treat numerous patients suffering from habitual constipation; I claim that this is a preventable malady and that the continued use of purgatives is irrational.

\section{Why the Abuse of Purgatives Continues}

The general practitioner is apt to be discouraged by many obstacles which prevent the effective treatment of habitual constipation. First, he is seldom instructed adequately on this subject while at hospital. Secondly, the diagnosis of habitual constipation can only be made by the patient, who is often misleading. Thirdly, no single factor can be blamed as the cause of constipation, and effective treatment must take into account all the circumstances in each case. At least four factors are commonly encountered:

1. The ignoring of the bowel habit or its lack of development.

2. Lack of physical activity.

3. Abuse of purgatives.

4. Unsuitable diets or artificially purified foods.

It follows that the treatment of habitual constipation is chiefly instructional. In actual practice this is so difficult that few doctors will make the attempt. Many patients have sedentary occupations, while others cannot afford a suitable diet. Moreover, there is nothing more difficult than to inculcate a habit into patients who have no use for any advice that requires personal trouble or thought. The rational treatment which at present is accepted by the medical profession does not utilize diet to the fullest advantage and, even when applied correctly, often fails altogether or only partially succeeds. It is discouraging for the doctor to take the time and trouble necessary to instruct his patients when his advice is not likely to be followed or, when utilized, is apt to fail. For these reasons the everyday treatment of constipation is largely disowned by the medical profession and is considered as the responsibility of the individual sufferer or parent; and patient, parent, and physician are all more concerned with the relief of attacks of constipation than with the prevention of their occurrence.

Purgatives appear to offer a simple and effective solution for doctor and patient. Under the term "purgative" I include aperients, salines, and all laxatives that are not purely mechanical. Not one of these "medicines" is physiological in action. I firmly balieve that the frequent use of purgatives is responsible for numerous minor ailments, especially digestive disorders, headaches, and nervous irritability. 


\section{Diet in Constipation}

As constipation is practically unknown among savage tribes it would appear that a method is required which will overcome the disadvantages of our civilized diets and sedentary occupations. Such a method should aim at increasing the normal reflexes without hurrying food through the intestine before it is properly digested. With this object I have used diets with a high-fibre content, such as bran. This method of treatment is founded on the theory that the colon does not function normally unless it has a certain amount of cellulose residue in its lumen after the processes of digestion have been completed. Though every normal diet contains some of this residue the major part of it is eliminated by the modern preparation of food. It is the virtue of this treatment that it remedies this artificial deficiency and thus, in my opinion, prevents the induction of constipation. The advantages I claim for the method are that it is simple, inexpensive, harmless, effective, and essentially physiological. As the use of food containing fibre has fallen into undeserved disrepute, and the value of diet for constipation has been grossly underestimated, I propcse to give a short elaboration of recent work on this subject.

There is now ample experimental evidence showing that the laxative effect of vegetable foodstuffs depends upon their "fibre" content. The most important investigations on this subject have been done by G. R. Cowgill and Anderson (1932-3), G. A. Williams (1927), H. Morgan (1934), and W. H. Olmsted $(1934,1935)$. The type of fibre contained in vegetable food varies in the extent to which it resists the action of bacterial decomposition and the digestive juices. On this fact depends the value of the foodstuffs as a laxative agent. Thus the fibre of green vegetables and ordinary foodstuffs is more readily broken down in the alimentary tract than is that of wheat bran. This explains why the addition of fruit and vegetables to the diet so often fails to prevent constipation.

\section{The Use of Bran}

Cowgill (1933) states that the fibre of " processed" bran resists decomposition to a very considerable degree, and that as the use of bran is not attended with undesirable symptoms of any kind this product may be considered to have special value for constipated patients. Cowgill and Anderson (1932) showed that when a low-fibre diet is given to normal people they become constipated, and that a "physiological fibre minimum" of $90 \mathrm{mg}$. per kilogramme of body weight daily is necessary to prevent constipation in healthy individuals.

There have been repeated statements by clinicians that the foods which contain fibre, and bran in particular, irritate the alimentary tract. Although no proof has been forthcoming to support these opinions they have been widely accepted. In order to determine this point investigations have been carried out by Murphy and Jones (1926), Frey (1928), and Rose (1932) with various types of diet containing up to 50 per cent. of fibre. No evidence of irritation was found. In a summary of literature M. S. Rose (1932) stated that from the use of bran " injury to the alimentary tract has not been observed." From my experience of the employment of bran during the last five years I have yet to encounter any signs or symptoms of irritation. I have used it for approximately 250 patients, old and young, in bed or at work, for those liable to peptic ulcer as well as for those with haemorrhoids, mucous colitis, and spastic colon. The only troubles ex- perienced were with a few patients who disliked eating bran or had difficulty in chewing it, or who complained of the lack of variety of these products.

Some writers state that bran "distends" the intestines, implying stretching of the gut wall to a harmful extent, but as bran forms a soft pulpy mass it would require accumulation behind an obstruction to produce abnormal distension. Objections have been raised because of the possibility of intestinal obstruction by bran. This is a bogy: when used correctly bran cannot cause obstruction, though in rare cases this has occurred when bran has been taken despite stubborn constipation.

Fibre by virtue of its power to retain moisture is a mechanical laxative. Under conditions of intestinal stasis it is gradually dehydrated, and therefore is useless for the relief of established constipation. Bran and all dietetic measures relying on the action of fibre should only be used for prevention of constipation. I believe clinicians have discredited bran because they have found it to fail when the patient is constipated, in other words when this form of treatment is not indicated. The erroneous impressions gathered from the incorrect use of bran has been perpetuated by the labelling of this substance "roughage." This term implies a coarse mechanical irritant. The soft moist stools produced when bran is used correctly cannot irritate the mucous membrane. Bran is also labelled "indigestible," whereas it is merely inert and certainly does not give rise to indigestion. Any person who can eat fruit and vegetables with impunity, can obtain proof of the harmlessness and effectiveness of bran by taking one of the processed products himself. These processed products are not made from the husk or chaff of wheat, but from the outer layers of the wheat or rice grain. They are made palatable with malt and sugar, and contain 5 to 15 per cent. of fibre.

\section{Technique of Use}

The instructions to the patients are given under two headings: (1) treatment of constipation if present; (2) prevention of future constipation.

(1) Most constipated patients know which " medicine" suits them and how much to take. The practitioner should be prepared to treat each patient as an individual in the matter of laxatives, and the patient's confidence will be retained if he is allowed to use the medicine that has been successful on previous occasions. The patient should be instructed to avoid purgation. When mild constipation is present I prefer "magnesia" or emulsions of liquid paraffin, which at first may be given in half-ounce doses morning and night. Senna or a pill such as pil. aloin co. may be used in moderately severe cases. Glycerin suppositories are also useful. For stubborn cases enemata consisting of plain water or saline are much more satisfactory than large doses of purgatives.

(2) I have used bran as the mainstay of my treatment, combined with the use of a laxative as long as is necessary. Bran should not be added to the diet when constipation is actually present. The bran should be taken daily for a minimum period of four weeks, and as laxation increases the laxative given may be gradually reduced and finaily left off. Bran is usually taken with milk and sugar for breakfast or the evening meal. Some people like to mix it with other breakfast cereals or porridge. The amount taken varies from one tablespoonful to a large cupful. Half a teacupful is an average quantity. In stubborn cases it may be necessary to give bran twice a day before the patient's usual dose of purgatives can be reduced. I have not found that the effect of the bran diminishes with use, 
nor that more is required; rather there is a tendency for patients to return to normal bowel habits and for less bran to be necessary.

\section{The Patients}

Eighty per cent. (121 cases) of my patients suffering from habitual constipation have utilized the bran method of treatment. Of the remaining 20 per cent. 8 per cent. were relieved by increased exercise and vegetarian diet and the omitting of purgatives, and the remaining 12 per cent. did not care for the method.

The 121 cases which form the material of my follow-up consist of 110 cases of simple habitual constipation, nine of spastic colon, and two of mucous colitis.

\section{Simple Habitual Constipation}

The following table gives the men and women under the classification that I have adopted:

\begin{tabular}{|c|c|c|c|c|}
\hline Type of Result & $\begin{array}{l}\text { No. of } \\
\text { Women }\end{array}$ & $\begin{array}{l}\text { No. of } \\
\text { Men }\end{array}$ & Total & $\begin{array}{c}\text { Per- } \\
\text { centage }\end{array}$ \\
\hline 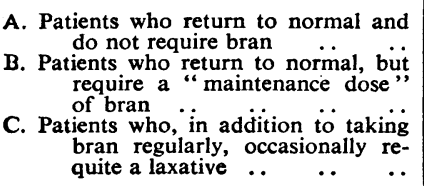 & $\begin{array}{l}28 \\
41 \\
5\end{array}$ & 14 & $\begin{array}{l}42 \\
57 \\
5\end{array}$ & $\begin{array}{l}38 \\
52 \\
4.5\end{array}$ \\
\hline $\begin{array}{c}\text { patients who have not been im- } \\
\text { proved-that is, failures }\end{array}$ & 6 & - & 6 & 5.5 \\
\hline Total .. $\quad \ldots \quad \ldots$ & 80 & 30 & 110 & 100 \\
\hline
\end{tabular}

Thus 90 per cent. of my patients (Types $A$ and B) have become normal and a further 4.5 per cent. approximately normal (Type C).

Type A.-Once a patient has succeeded with bran he or she rarely reverts to purgatives again except in an emergency. The patients who become quite normal usually find that a little bran helps them out of any future tendency to constipation. The time taken to attain normality varies considerably. Some are immediately successful, and others after a period of years find that bran can be left off.

Type B.-Most of the patients in this group have had long-standing constipation, or have poor musculature and/or sedentary habits. They require a "maintenance dose" of bran. This group also includes those patients who need bran only once or twice a week, and some who have started treatment recently and may be able to leave it off later.

Type C.-All these patients were women, and had had severe constipation as long as they could remember. No previous method had given them a satisfactory result, but they now obtain regularity when taking bran together with a mild laxative such as magnesia. It is significant that although none of these particular patients like eating bran they all continue to take it.

Type D.-There were six women patients who did not find bran useful after a prolonged trial. These patients were all in the same age group, the youngest being 37 and the eldest 50 . It is well recognized that constipation is prevalent and difficult at the time of the menopause, also that laxation is affected by the monthly periods. In contrast to the other groups no increase in the amount of stool passed was noticed by these patients. This would tend to support a suggestion by Cowgill (1933) that in constipated patients fibre is more readily broken down in the alimentary tract than in normal people.
Of fifteen patients who at first disliked eating bran but who were willing to take it, only four have reverted to other methods.

When I divided my patients into two groups-(i) those constipated more than ten years, (ii) those constipated less than ten years - I found all but one of the failures and partial failures had been constipated for more than ten years. Further, those patients who had been constipated for a long time recovered less easily. In contrast to this the apparent severity of the constipation did not influence the prognosis as much as the length of history.

\section{Use of Bran in Special Conditions}

1. Haemorrhoids.-Seven of my patients had symptoms of haemorrhoids when treatment began and eleven others gave a history of haemorrhoids. When haemorrhoids were present the degree of laxation aimed at was two formed soft stools each day until symptoms disappeared. Otherwise the treatment was similar to that used for uncomplicated constipation. There have been good results in every case, the haemorrhoids disappearing without any special or local treatment. In no instance did the use of bran increase the symptoms, nor has there been any recurrence. The eighteen patients in this group have been particularly pleased with the bran treatment.

2. Mucous Colitis.-The two cases I treated were both attributable to purgatives; they lost all symptoms, including mucus, within two months, and have not relapsed during the last two and three years respectively.

3. Spastic: Colon.-These cases offer an excellent opportunity for preventive medicine. My experience has led me firmly to believe that constipation provokes the "attacks" in susceptible persons. Almost all of these patients have habitual constipation ; I have found this can be prevented by the use of bran, and then attacks of spasticity are very unlikely. It is perfectly. clear to those engaged in private practice that the attacks are short and the intervals long. Good results from the use of bran are not to be expected when spasticity is present, for the patient is constipated. In my opinion the reason why bran has been regarded as irritating in this condition is because there has been no distinction between the "attack" and the "interval."

\section{Psychology}

Everyone who has treated individuals suffering from constipation realizes that a strong psychological element is involved. The patients are apt to think that they are ill, and the necessity for taking medicine confirms them in this view. Bran is regarded as a food, not as a medicine, by the lay public, and the patient who secures satisfactory laxation by the use of bran rapidly ceases to regard himself as a person requiring treatment, and his hypochondria diminishes correspondingly. My experience. is that patients who are successful with bran have a psychological advantage over those who are successful with laxatives. Bran taken as a cereal at mealtime becomes a habit and does not tax the memory. When stabilized the exact dose is unimportant. A missed day does not give rise to anxiety or call for interference, as an action is certain on the following day. Moreover, there is a prolonged hang-over action, laxation continuing normally for several days after the bran has been left off. The great majority of my patients have attained normality, and the subject of laxation has then become unimportant.

The improvement in these patients is so striking in the majority of cases that few attend sufficiently often to facilitate a "follow-up." The value of the treatment is 
only ascertained at the time of the next ailment. This amnesia does not occur when purgatives and mechanical laxatives are taken. It is necessary to remember to take "medicine" and to gauge the dosage with the results cbtained. It is seldom that they produce the clocklike regularity experienced with bran. Many patients who take purgatives experience symptoms such as flatulence, headaches, colicky abdominal pain, and sometimes alternate between constipation and diarrhoea. In such circumstances how can they be anything but "colonminded "?

\section{Prophylaxis}

Bran may be used as a prophylactic agent to prevent the occurrence of constipation in patients who are: (a) constitutionally liable to constipation; $(b)$ placed in circumstances which may produce constipation.

(a) Some patients who are liable to attacks of constipation ward them off with bran once a week. Its action gradually diminishes over a period of three to eight days in the patients who find it effective in this way. I believe that bran is a useful prophylactic against the attacks of spastic colon.

(b) Bran can be used during the post-operative, antenatal, and post-natal periods. Other laxatives are often necessary as well, but it is not difficult to minimize them, especially if the patient has used bran previously. As the occurrence of constipation often dates from childbirth or an abdominal operation, prevention of constipation is particularly important at these times. The influence of different localities on the laxation of certain people has never been satisfactorily explained. The water supply has been indicted, but a recognized authority on water supplies (Thresh, 1932) states that hard water is not known to cause constipation. One of my patients who varies between normality in Hampshire and obstinate constipation in Hertfordshire has obtained no benefit from the use of a water softener. Many people become constipated when travelling, and bran as a prophylactic is much superior to the purgatives usually employed.

\section{Summary}

The principle for the use of high-fibre diets for constipation has not been appreciated. High-fibre diets should be used for prevention and not for treatment.

Investigations have shown that: (1) the laxative value of foodstuffs depends upon the type of fibre contained therein ; (2) the fibre of wheat bran is much more effective than that of fruit and vegetables; (3) no evidence of irritation of the alimentary tract by bran has been observed.

The nomenclature in common use has been criticized.

One hundred and twenty-one patients with habitual constipation, 80 per cent. of the total, were treated with processed bran. The results in 110 cases of simple habitual constipation showed that: the treatment was successful in restoring normal bowel habits in 90 per cent. of the cases; that women were more common sufferers than men in 3 to 1 ratio; that the menopausal age is the most difficult; and that the prognosis and rapidity of response to treatment depend upon the length of the history of constipation.

The psychological benefit conferred on these patients is contrasted with the outlook of the patient taking laxatives.

The importance of prophylaxis is emphasized.

The results in patients with haemorrhoids were particularly encouraging.
Two cases of mucous colitis due to purgatives were successfully treated by bran.

In spastic colon the importance of the prevention of constipation during the intervals between the attacks is emphasized, for it is suggested that constipation induces spasticity in the susceptible person.

The processed bran used in the investigations was Kellogg's All-Bran.

REFERENCES

Cowgill, G. R., and Anderson, W. E. (1932), J. Amer. med. Ass. 98, 1866

Frey, et al. (1933). Ibid., 100, 795

Frey, J. W., et al. (1928). Med. J. and Rec., 127, 585

Morgan, H. (1934). J. Amer. med. Ass., 102, 995.

Murphy, J. C.. and Jones, D. B. (1926). J. biol. Chem., 69, 85 Olmsted, W. H., et al. (1934). Proc. Soc. exp. Biol., N.Y., 32 141 .

Rose, M. S., et al. (1932). J. Amer. diet. Ass., 8, 133.

Thresh, J. C., Beale, J., and Suckling, E. (1932). Water and Water Supplies, p. 247.

Williams, G. A. (1927). Amer. J. Physiol., 83, 1.

Witts, L. J. (1937). Lancet, 1, 427.

\section{TREATMENT OF CARCINOMA BY IN- SERTED RADIUM PLAQUES}

BY

\section{H. S. SOUTTAR, Ch.M., F.R.C.S. Surgeon to the London Hospital}

Probably the most important factors in the successful irradiation of carcinoma are that the irradiation should be uniform over the whole region under treatment and that its amount should be accurately known. In the possibility of satisfying these conditions lies the real advantage of radiation from a distance, whether by large radium units or by $x$ rays.

The insertion of seeds or needles into the tissues, however skilfally carried out, can only give a very rough approximation to the result desired, and in any event there must be a number of points of excessive irradiation and local destruction of tissue. The method which I propose to describe avoids such local damage while retaining the convenience and economy of seeds and needles; moreover, in the regions where it is applicable it would appear to meet with a high degree of accuracy the conditions we have stated as fundamental.

\section{Method of Procedure}

The method consists in the introduction into the tissues of small plaques made of dental wax and carrying within the wax the seeds or needles used as sources of radiation. The latter are so arranged as to give the flattest possible

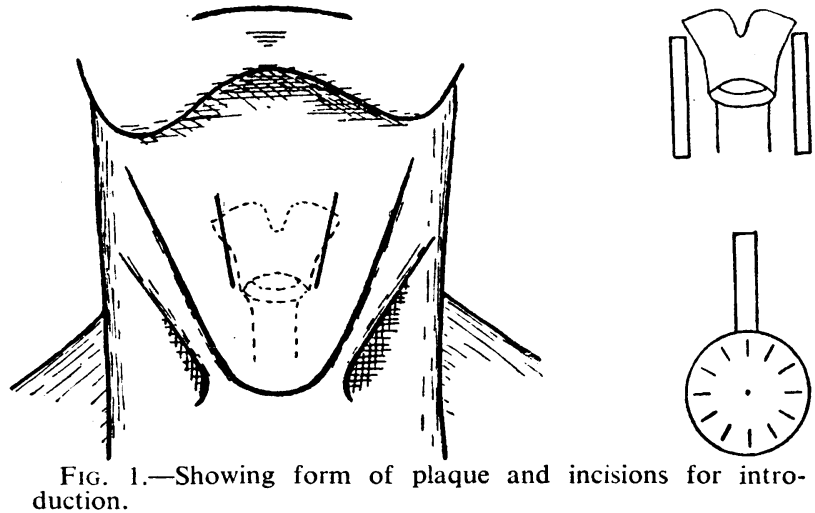

field, and where it is possible to introduce two opposing plaques these can be so arranged that the whole of the intervening tissue receives an almost uniform radiation. 